\title{
Reflection on the 12th International Moral Competence-Symposium in Chemnitz (11th to 13th October 2018)
}

\author{
Martina Reinicke \\ (Berufliches Schulzentrum Döbeln-Mittweida, m.reinicke@primacom.net)
}

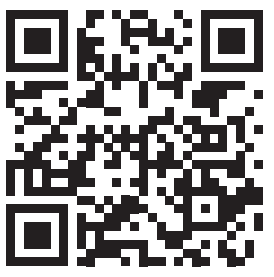

The $12^{\text {th }}$ International Moral Competence Symposium from 11th to 13th October 2018 this year took place in Chemnitz, in Pentagon3. Chemnitz is also a place where traditional inventive spirit and ingenuity meets the newest developments of the 21st century. Chemnitz University of Technology and the many research institutes based here are testament to the city's status as leading national research and development centre. But in the last weeks we experienced that some backward, nationalist people in Chemnitz lack moral competence. Therefore, it was the right place to have the $12^{\text {th }}$ International Moral Competence Symposium here. Its theme: "Moral Competence: Its Nature, Its Relevance, and Its Education." The Moral Competence-Symposium brought together international scientists and practitioners with different professional backgrounds from all over the world: the participants came from China, Poland, Sierra Leone, South-Korea, USA and Germany. Similarly, diverse was their professional back-ground: psychology, education, engineering, human resource management, employment facilitation, and philosophy. Special guest was Prof. Dr. Georg Lind, the creator of the Moral Competence Test (MCT), the Konstanz Method of Dilemma Discussion (KMDD ${ }^{\circledR}$ ), and the KMDD-Training and Certification Program. The participants had an intensive exchange of their experiences, research findings and questions regarding the $\mathrm{KMDD}^{\circledR}$ and $\mathrm{MCT}^{\circledR}$ during the sessions and the breaks and the evening dinners. In the spare time, the participants could take part in two guided city tours, so that they could see how beautiful Chemnitz is, in spite of the destructions during World War 2 and the non-so-beautiful architecture of the GDR-times.

\section{Workshop}

Before the Symposium Dr. Kay Hemmerling offered a half-day workshop on "How to work with the Moral Competence-Test?”. Participants could learn about the MCT $^{\circledR}$, its 
theoretical foundation, its functioning and its application.

\section{Keynote}

After some introductory words of Martina Reinicke (Coordinator of the $12^{\text {th }}$ Symposium), Dr. Georg Lind opened the $12^{\text {th }}$ Moral Competence-Symposium with his keynote address on "The nature of Moral Competence, its relevance and its teachability." He started with his definition of moral competence "as the ability to solve problems and conflicts on the basis of one's moral orientations (moral ideals like humanism, justice, freedom, health, competence and others) through thinking and discussion, instead of through violence, deceit, or bowing down to others" (Lind 2018).

He emphasized the fact that there is no single morality but that we have to clearly distinguish between two different aspects of morality: the cognitive aspect (moral competence) as well as the affective aspect (moral orientation). Although they are clearly different they are inseparable and cannot be measured separately. So, in future we must speak any more about morality without saying which aspect we mean.

Both aspects can be measured simultaneously with the Moral Competence Test. This experimental questionnaire is the first measurement instrument which allows the assessment of internal moral competence in an objective way, Lind said. Since its publication in the mid-1970s, moral competence has become an important new topic in psychology, education, philosophy, political science and many other fields. Lind explained that many correlational and also experimental studies with the $\mathrm{MCT}^{\circledR}$ have shown that it is of eminent importance for our social behaviour: law-abiding, staying honest, keeping contracts, rejecting false authority, helping, mental health, whistle-blowing, swift decision-making, learning performance, etc. All this behaviour is vital for living together in a pluralistic democracy. Therefore, fostering moral competence is urgently needed. 'Moral orientations are inborn in most, if not all, people. Moral Competence is the strongest known factor of people's social behaviour and does not be develop by itself. More, it regresses when not being used. Its development requires opportunities for using it.' Morality can be effectively fostered with The Konstanz Method of Dilemma Discussion and similar methods like the Discussion Theatre and other democratic and inclusive learning methods. Research on the efficiency of these methods is also needed.

After Dr. Lind's keynote address, the participants discussed intensively about the new demands concerning moral education. The discussion was moderated by Dr. Kay Hemmerling.

\section{Presentations}

The presentations showed not only what has been achieved in the field of moral competence research and education but also opened completely new perspectives: 
Dr. André Schmiljun (associated with Adam Mickiewicz University in Poznań) started his lecture with the question "Why we cannot regard robots as people, but rather as ends in themselves." In other words: Does our current methods and theories of persons match with the raising of Artificial Intelligence? After outlining common theories of person, Schmiljun discussed definitional problems and logical problems of these theories. He argued that they exclude either human beings or robots from personhood. In the second part of his presentation he demonstrated a new approach based on Christine Korsgaard's interpretation of Kant, he illustrated that's possible to leave out complicated notions like "person" in the debate, without denying robots' status as moral agents.

Prof. Marina Klimenko (associated with University of Florida) presented findings of her online education study. Online education is becoming increasingly popular in public and private education. The purpose of her study with 300 students was to examine effectiveness of two different online psychology courses for fostering competence, empathy and course performance. The students were taught about moral development and the factors affecting it. In addition, students had to engage in an online-group discussion where they reflected and discussed upon at least one moral dilemma-story. Results revealed that it's possible to increase moral competence with online education and that the utilization of cognitive aspects of empathy leads to an even bigger increase of moral competence.

Democracy, Dr. Georg Lind argued, depends on the ability of its members to solve problems and conflicts on the basis of moral principles through thinking and discussion, instead of through violence, deceit, or submission to others. Lind presented "Discussion Theatre" as a new way to foster this ability, which he calls moral-democratic competence. In this new form of theatre there are no actors and spectators but all are participants. In nine sets, they hear a dilemma-story, think about it, deliberate about the moral principles and dilemma(s) involved, vote about the protagonist's decision in the story, discuss whether it was right or wrong, nominate best counter arguments, and reflect on the learning effect of the whole play. The Discussion Theatre provides a space for thinking and discussion free of anxiety and threat by an authority.

Yueming Hou from the Chinese University of Physical Education and Sports Science in Guangzhou explored question how one can foster moral competence through group sport like park running. He interviewed participants of a weekly timed 5-km park-run, which takes place in public parks. He scored his interviews for traits like accessibility, inclusivity, gaining and giving. Yueming Hou's assumption is that activity incentives such as equality, freedom, membership as well as real interaction between participants (between faster and slower runners) during runs promote moral competence.

Dr. Małgorzata Steć (associated with Jesuit University Ignatium in Kraków) presented her research on the question whether the KMDD ${ }^{\circledR}$ influence moral competence in university students and which factors may moderate its effects. She examined 65 intramural and extramural students with and without $\mathrm{KMDD}^{\circledR}$ sessions. Steć found that 
the increase of C-scores in experimental groups, in which $\mathrm{KMDD}^{\circledR}$ has been conducted twice between MCT $^{\circledR}$ Pre-test and Post-test, was higher than in control groups in which there were no KMDD ${ }^{\circledR}$ sessions. Apart from taking part in $\mathrm{KMDD}^{\circledR}$ sessions, the increase of moral competence was also influence by other factors. Stec plans to study these other factors in future research.

Prof. J. A. Y. Park from Gyeongsang National University in South Korea. Park suggested a modification of the algorithm for the C-index. He suggested to combine both aspects so that participants with low moral orientations would not get a high moral competence score. For this purpose, Park works with simulated seldom cases in which a C-score of nearly or of exactly hundred were achieved. First tests conducted by Park gave hints that it's necessary to reformulate some arguments to ensure and improve theoretical validity of the MCT $^{\circledR}$. It's necessary, so Park, to create better arguments, especially regarding neighbour Kohlberg-stages for better and more exactly showing on which stage a tested person is. In his reply, Dr. Lind reminded us that the MCT $^{\circledR}$ does not measure Kohlbergian stages and therefore no changes of it are needed.

On the last day the main focus of the $12^{\text {th }}$ International Moral Competence Symposium was on practical experiences of moral education in schools and other institutions.

Dr. Kay Hemmerling spoke about his experiences in a prison in Berlin where he, together with Matthias Scharlipp, carried out an intervention project with inmates (criminal from different countries). He was able to show that prisoners' moral competence could very much profit from the KMDD ${ }^{\circledR}$. Prisioners as well as non-prisoners prefer high moral ideals like justice and responsibility. However, they have a lower moral competence. Moreover, their moral competence regresses the longer they stay in prison. Hemmerling's study shows that this regression can be stopped and that it's possible to improve their moral competence with KMDD sessions. His study and findings are reported at length in his book "Morality Behind Bars. An Intervention Study on Fostering Moral Competence of Prisoners as a New Approach to Social Rehabilitation." In addition to his presentation and by way of illustration, Dr. Hemmerling showed a short film in which the prisoners discussed a dilemma story. Thereafter, the participants of the Symposium asked questions and discussed his presentation.

As the final presenter, Martina Reinicke presented her book "Moral Competence Reloaded." She is an ethics teacher and a KMDD teacher with a life-time certificate. Martina Reinicke explained and described her motivation of writing a book: in our school lacks moral education. Therefore, Martina Reinicke wrote the book "Moral Competence Reloaded", and she mainly tries with it to answer to three questions in an understandable and entertaining way. 'What is moral competence?'; 'Is moral competence important?' and 'Can moral competence be taught?' Reinicke describes in her book why and how can be taught morality. Based on the Georg Lind's theory of moral education, she writes about her experiences with $\mathrm{KMDD}^{\circledR}$ and $\mathrm{MCT}^{\circledR}$ in every day school live. By using dilemma stories and anecdotes of everyday school life, she describes what's necessary to do for 
closing the gap between the own moral beliefs and the own actual behaviour. At the end of her presentation, Martina Reinicke showed a short video-document about a KMDD session in a class of German students and of Afghan refugees, who could hardly speak German because they had only shortly before arrived in Germany. The film showed how the KMDD ${ }^{\circledR}$ can help to integrate foreigners. Reinicke argues that the topic of integration and inclusion is closely related to moral competence: higher moral competence leads to a better inclusive behaviour of natives and foreigners as well.

\section{Conclusions}

Even though the participants of this symposium came from different countries, they soon found out that they had one thing in common: the desire to make the world a little bit fairer and better by fostering moral competence of the people. The presentations not only showed what has been achieved in the field of moral competence research and education, but also opened new perspectives for future research and educational practice.

'We know that democracy is a difficult way of living together', Georg Lind pointed out in his closing words. 'If citizens feel not able to live in a democracy, they reject it and vote for antidemocratic politicians. Moral competence does not develop by itself. We must foster moral competence by providing adequate learning opportunities.'

Our $12^{\text {th }}$ International Symposium on Moral Competence in Chemnitz surely contributed to this task. In that sense, it was a successful event.

The 13th International Symposium "Moral Competence: Its Nature, its Relevance, and its Education" is planned for 2019 in Konstanz.

Martina Reinicke (Chemnitz, October 2018)

\section{Photos of $12^{\text {th }}$ MC-Symposium}

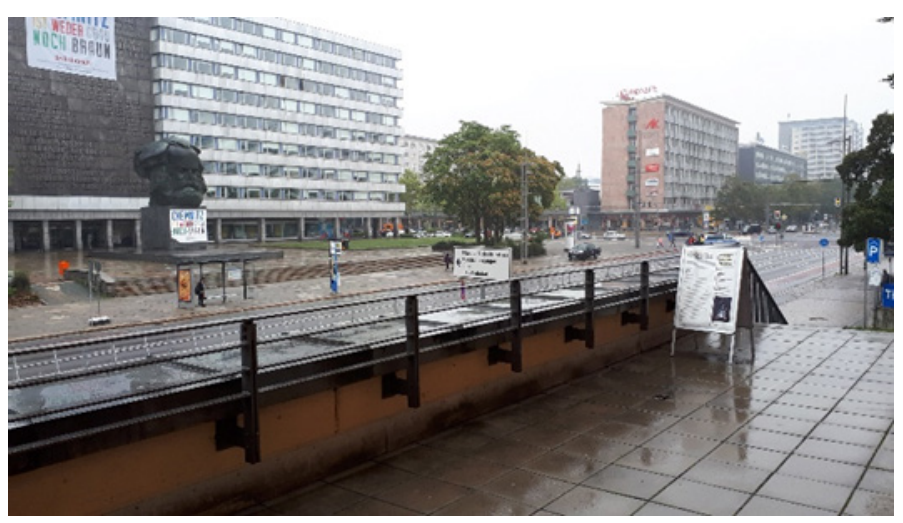

Advertising 


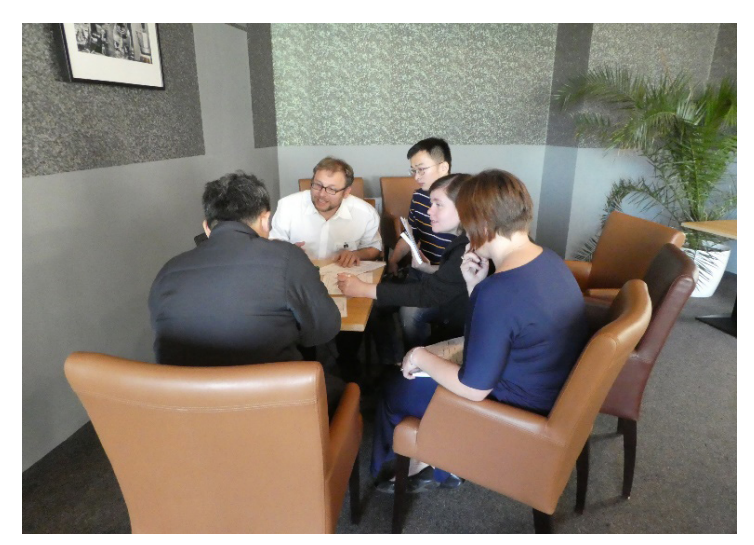

Workshop with Kay Hemmerling

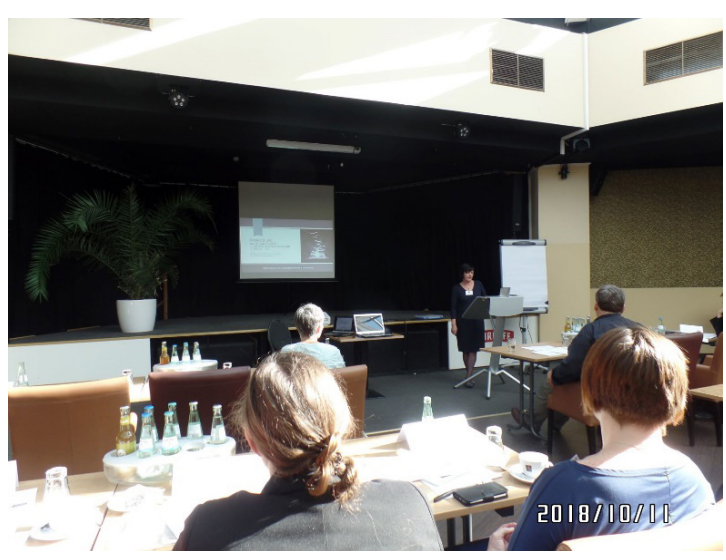

Opening speech by Martina Reinicke
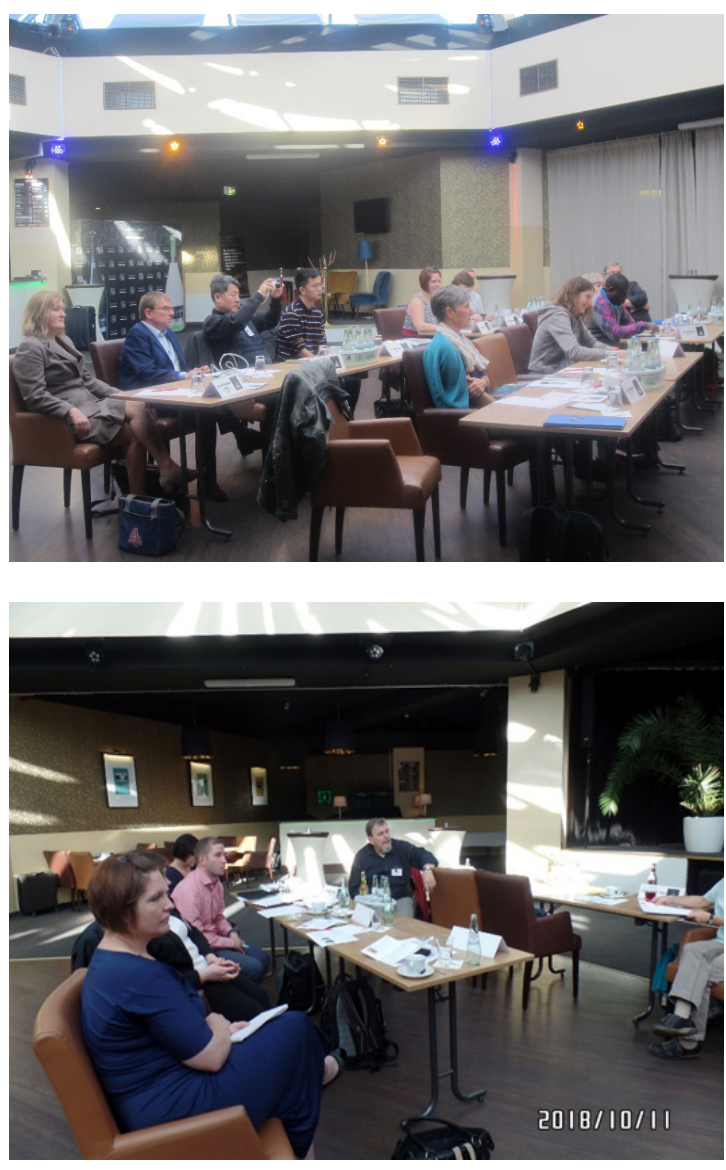

Panel discussion 

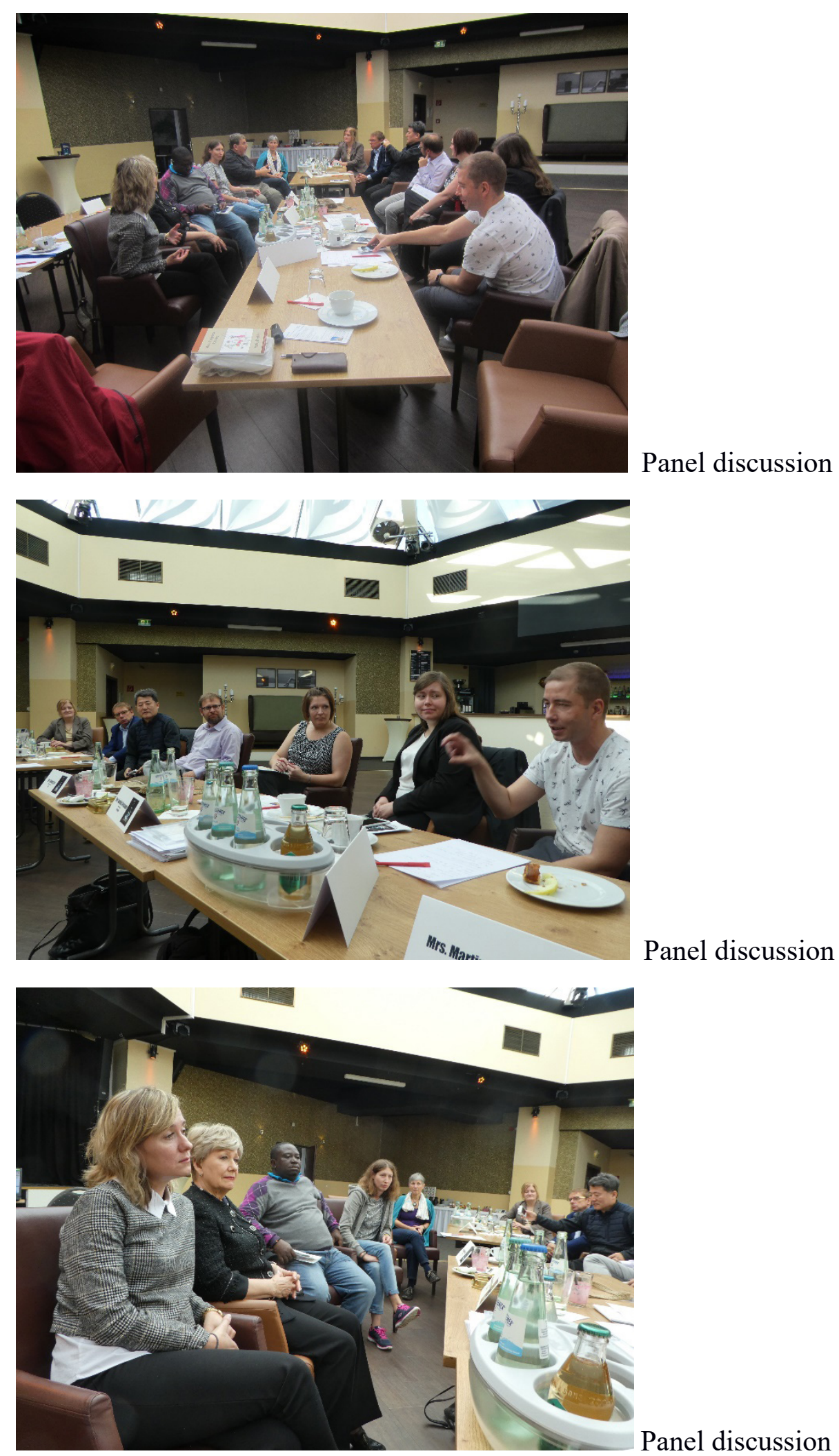


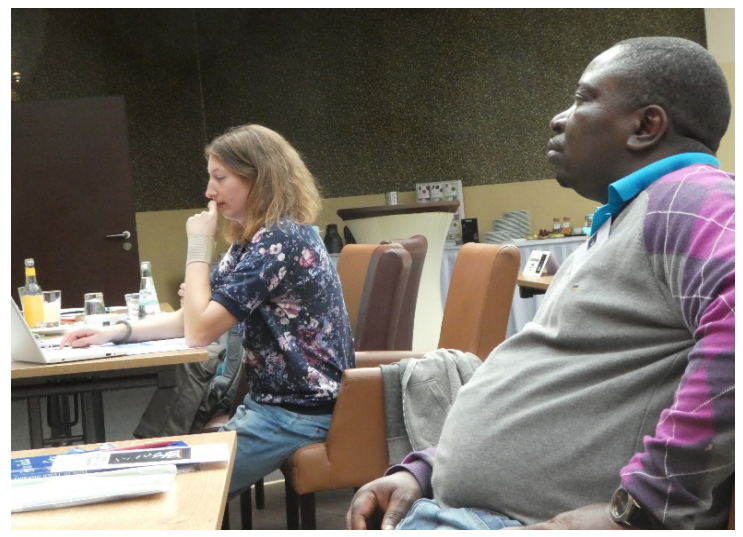

Gosia and Samuel Moody

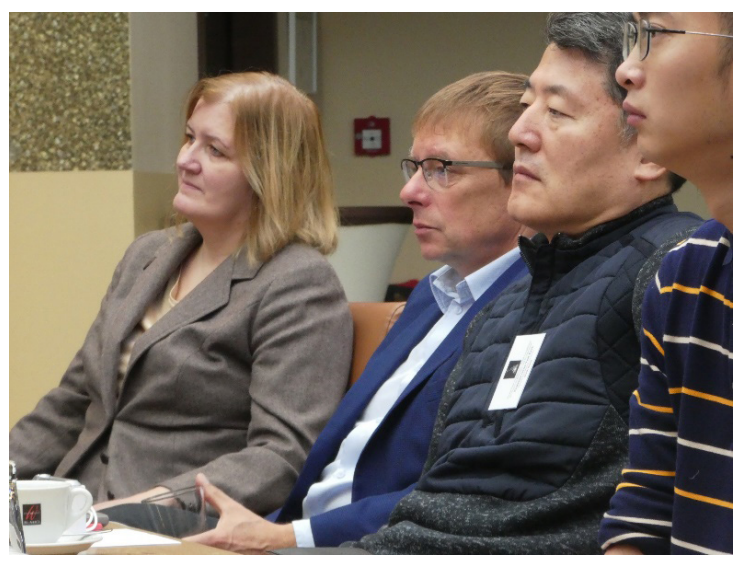

Hou, Prof. Park, Mr. \& Mrs. Smolak

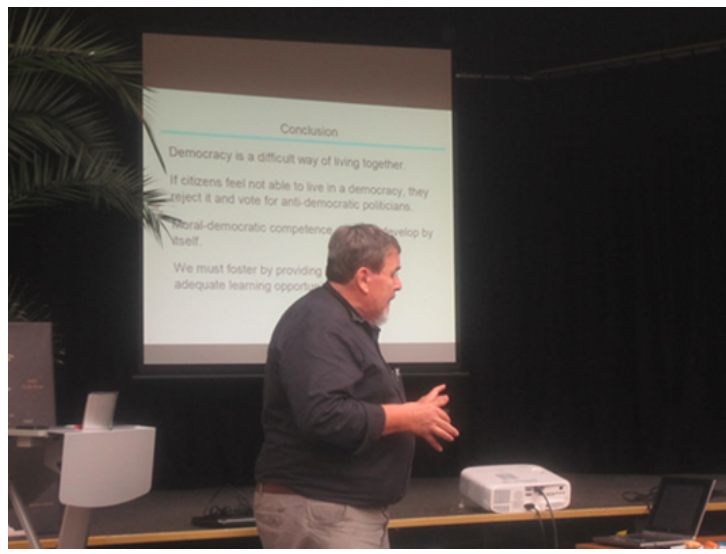

Georg Lind

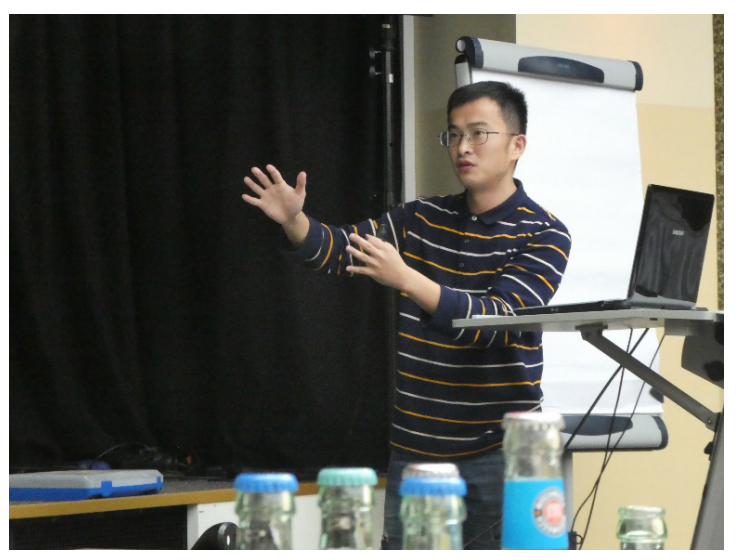

Hou Yueming 

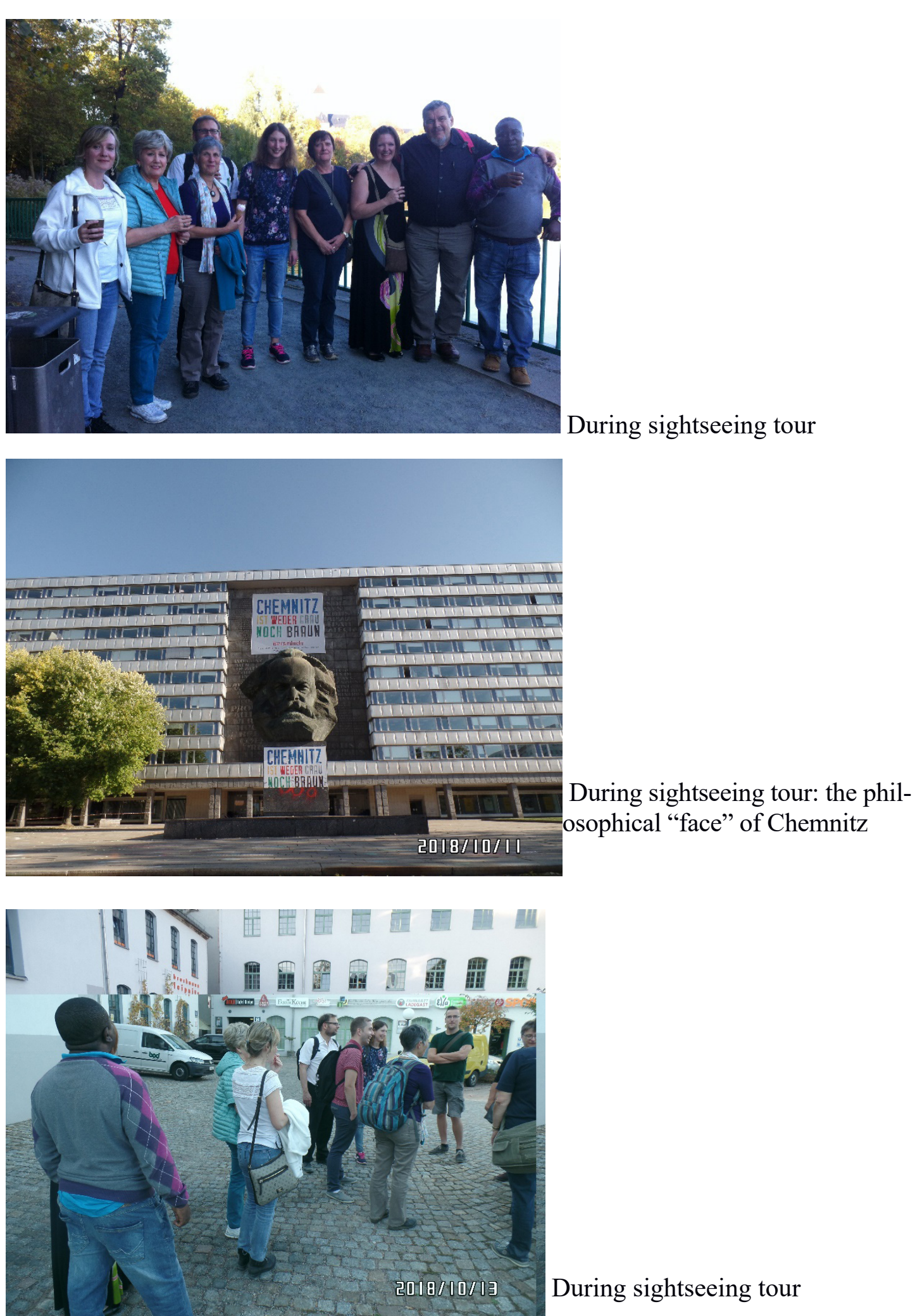

During sightseeing tour 

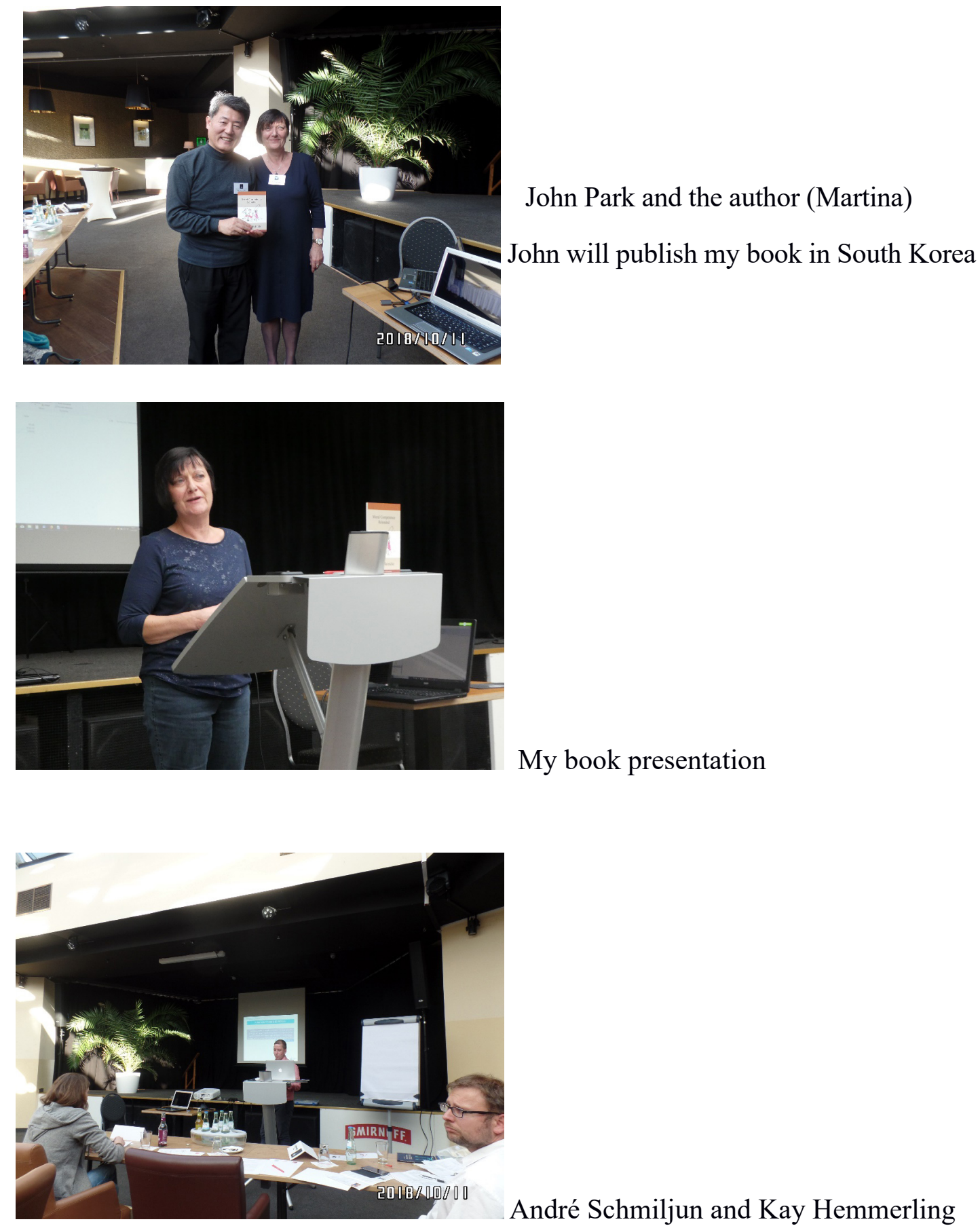

André Schmiljun and Kay Hemmerling

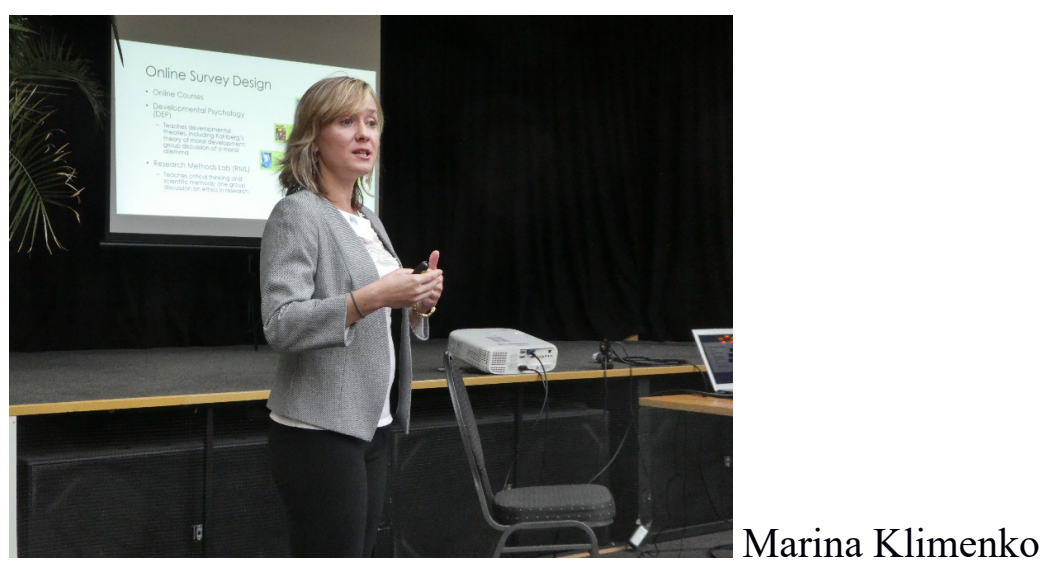




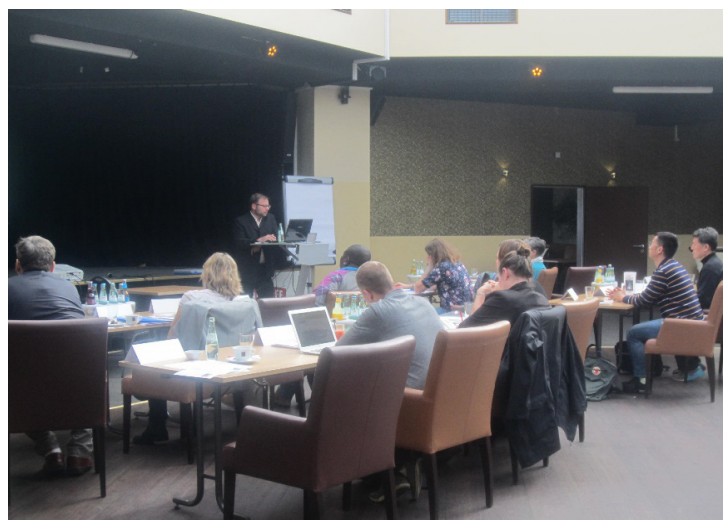

Kay Hemmerling

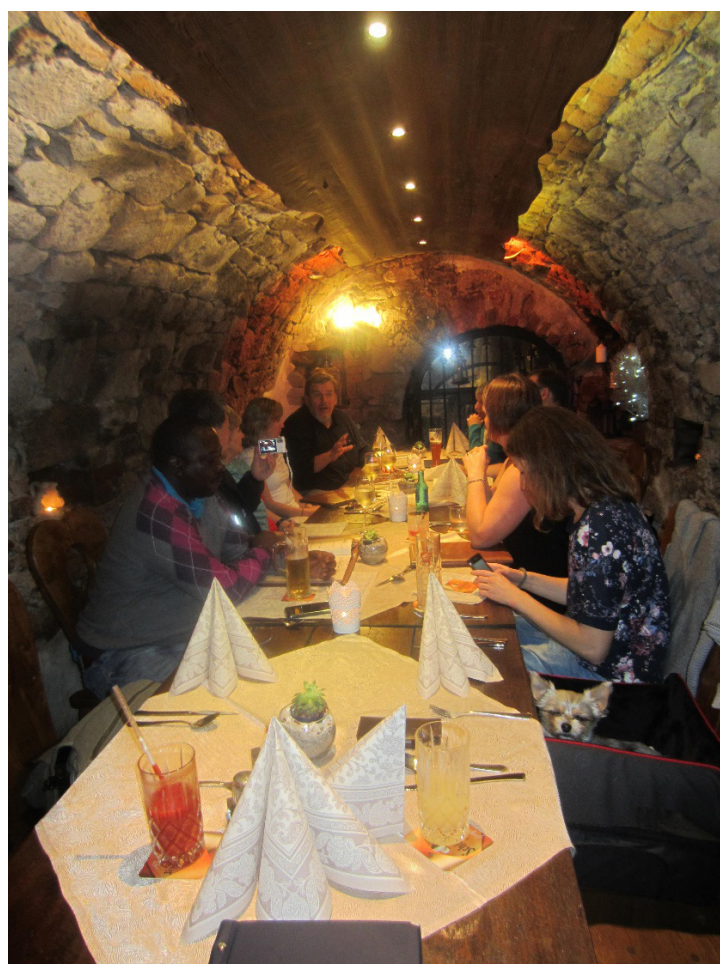

In the restaurant "Kellerhaus" - the oldest restaurant in Chemnitz

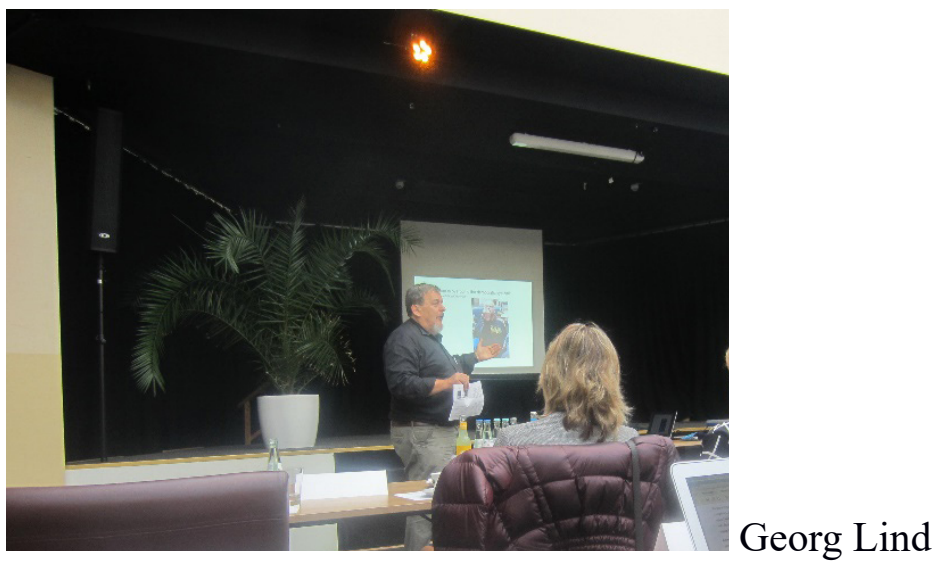



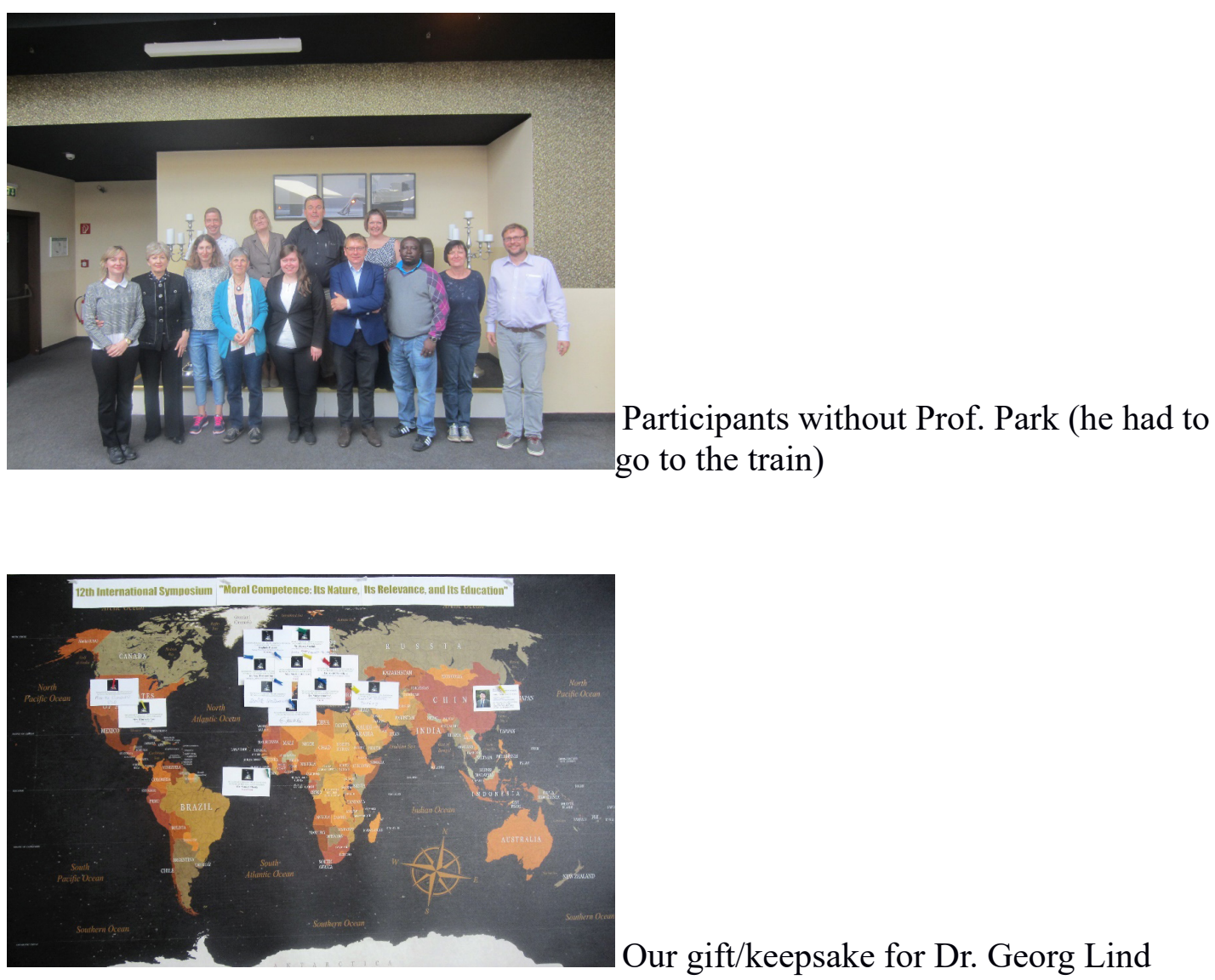

Ethics in Progress (ISSN 2084-9257). Vol. 9 (2018). No. 2, Art. \#1, pp. 4-15.

Creative Commons BY-SA 3.0

Doi: 10.14746/eip.2018.2.1 